\title{
Acute upper gastrointestinal bleeding in southern Saudi Arabia: A retrospective observational study
}

\author{
Mohammed Attieh Alzahrani ${ }^{1{ }^{*}}$, Mohammed Alfaifi ${ }^{2}$, Sultan Abdullah Alzaher ${ }^{2}$, Saad Shaker Saad ${ }^{2}$, Fahad Mohammed Alshehri ${ }^{3}$, \\ Mohammed Jameel Almatrafi ${ }^{3}$, Mushabab Saeed Hammad ${ }^{3}$, Khalid Yousef Nebrawi ${ }^{3}$, Abdullah Mohammed Alshehri ${ }^{3}$, Tamer \\ Mamdouh Elmalahy ${ }^{3}$, and Shahata F Shehata ${ }^{4,5}$
}

${ }^{1}$ Department of Medicine, College of Medicine, King Khalid University, Abha, Saudi Arabia; ${ }^{2}$ Department of Medicine, Assir Central Hospital, Abha, Saudi Arabia; ${ }^{3}$ Gastroenterology Division, Assir Central Hospital, Abha, Saudi Arabia; ${ }^{4}$ College of Medicine, King Khalid University, Abha, Saudi Arabia; ${ }^{5}$ High Institute of Public Health, Alexandria University, Egypt

\begin{abstract}
Context: Upper gastrointestinal bleeding (UGIB) is a common life-threatening emergency that carries considerable mortality and morbidity; it remains a common cause for admission to hospitals worldwide.

Aims: To describe present clinical manifestations in southern Saudi Arabian UGIB patients, including both endoscopic and basic laboratory parameters, to assess the risk factors, and compare the predictive power and clinical usefulness of three risk scoring systems for the management of patients presenting with UGIB.
\end{abstract}

Methods: This was a retrospective observational study. We included 283 patients admitted to the gastrointestinal unit at Abha city, southern Saudi Arabia, from November 2017 to October 2019.

Results: Ages ranged from 18 to 97 years old with mean age of $54.5 \pm 18.5$ years. The majority of patients were males (72\%; 203). Melina was the most common presenting symptom, in 66 (49.3\%) patients. Diabetes mellitus was the most frequently recorded risk factor for UGIB (53.9\%) followed by hypertension (44.9\%), and aspirin use (35.7\%). Endoscopic hemostatic treatment was applied in 70 patients $(24.7 \%)$; $4.9 \%$ of patients re-bled, and 21 patients (7.4\%) died during the study period.

Conclusions: Comorbidities such as hypertension and diabetes, in addition to some medicines including ASA, steroids and NSAIDs were identified as risk factors of upper GIT bleeding among this study casesa list of risk factors for severe UGIB, leading to hospitalization and even death.

Keywords: upper gastrointestinal bleeding; UGIB; hemostatic treatment; re-bleeding; variceal

*Correspondence author: Mohammed Attieh Alzahrani, Assistant Professor, Department of Internal Medicine, College of Medicine, King Khalid University, P.O Box 641, Abha, Zip code: 61421, Kingdom of Saudi Arabia. Tel: 00966504586134; Email: mohammedalzahrani641@gmail.com; dr_mohdaz@hotmail.com

Received 23 April 2019; Revised 15 June 2020; Accepted 20 June 2020; Published 25 June 2020

Citation: Alzahrani MA, Alfaifi M, Alzaher SA, Saad SS, Alshehri FM, Almatrafi MJ, Hammad MS, Nebrawi KY, Alshehri AM,
Elmalahy TM, Shehata SF. Acute upper gastrointestinal bleeding in southern Saudi Arabia: A retrospective observational study. J Med Sci Res. 2020; 8(3):105-113. DOI: http://dx.doi.org/10.17727/ JMSR.2020/8-15

Copyright: (c) 2020 Alzahrani MA et al. Published by KIMS Foundation and Research Center. This is an open-access article distributed under the terms of the Creative Commons Attribution License, which permits unrestricted use, distribution, and reproduction in any medium, provided the original author and source are credited. 


\section{Introduction}

Upper gastrointestinal bleeding (UGIB) is a common life-threatening emergency that carries considerable mortality and morbidity and is a common cause for admission to hospitals worldwide [1]. It is characterized by unusual haematemesis and coffee-ground emesis, with/or melena that occurs adjacent to the ligament of Treitz [2]. Currently, emergency esophagogastroduodenoscopy (EGD) is the preferred method of locating the origin of bleeding, evaluating the bleeding rate, interpreting the underlying pathology, and determining the intervention if necessary. However, emergency EGD might be unavailable because of lack of endoscopists and equipment [3]. UGIB is classified as variceal bleeding or non-variceal bleeding because of distinct etiologies and management [4]. Causes of variceal bleeding include esophageal or gastric varices, whereas causes of non-variceal bleeding are mainly peptic ulcers, erosive gastroduodenitis, reflux esophagitis, tumor, and vascular ectasia [3].

Longer life expectancy in almost all countries has led to increased occurrence of comorbid diseases, especially cardiovascular diseases. This has been associated with abuse of non-steroidal antiinflammatory drugs (NSAIDs), antiaggregants, and anticoagulants that are associated with numerous gastrointestinal problems, including peptic ulcer and gastrointestinal bleeding $[5,6]$, in addition to widespread obesity and opioid use, both of which are associated with higher risk of developing upper gastrointestinal bleeding [7]. These developments have been occurring during the same time period as major advances in preventive and treatment modalities, including the discovery of Helicobacter pylori, proton pump inhibitors, and other pharmacological therapies, as well as the development of novel endoscopic non-invasive and hemostatic modalities $[2,7]$.

Recent advances in pharmacologic and endoscopic management have led to re-bleeding and mortality of $10 \%-30 \%$ and $2 \%-15 \%$, respectively [8]. Nevertheless, higher risk of re-bleeding was associated with inaccurate endoscopic hemostasis and presence of comorbidities such as cirrhosis and chronic kidney disease, in addition to high levels of C-reactive protein and hemoglobin [1]. Universal guidelines proposed that subjects at low risk of rebleeding should be discharged soon after endoscopy [9].
The epidemiology of UGIB, according to hospitalbased studies, varies across regions and countries. Loperfido et al. measured the incidence UGIB in 1983-1985 and 2002-2004, and found that the UGIB incidence rate decreased from 112.5 to 89.8 per 100,000 individuals annually [10]. Similarly, in the USA, the incidence of UGIB hospitalizations decreased $21 \%$ from 81 per 100,000 in 2002 to 67 per 100,000 individuals in 2012. Nevertheless, more than 250,000 individuals are hospitalized due to upper gastrointestinal bleeding every year $[7,11]$.

We found that the incidence of UGIB in Saudi Arabia tended to be lower than that reported in western countries. Nevertheless, recent national studies are lacking. A large study carried between January 1980 and July 1994 in Riyadh showed that 4.9\% of endoscopies were carried out for UGIB [12]. Another report from Abha City, South Saudi Arabia, found the incidence of hospitalization for acute UGIB was 8.9\% [13]. In yet another recent study from western region of Saudi Arabia Central Hospital conducted from January 2015 to December 2017, there were 120 patients with UGIB over these three years [14].

Accurate classification of high-risk patients and identification of low risk patients can aid selection of appropriate candidates for early endoscopic intervention or close follow-up in supervised care contexts. Several risk scoring systems have been developed to help professionals predict mortality, re-bleeding rates, and treatment choices. The most frequent used are the Glasgow Blatchford score (GBS), the Rockall risk score (RS), and the recently described AIMS65 score (AIMS65). These scoring systems categorize findings in three ways: those scores using endoscopic findings only; those using clinical manifestations only; and those using both of endoscopic and clinical findings $[8,15]$.

Published data from the Saudi Arabia region do not do justice to this issue. Therefore, the aims of this study were to describe present clinical manifestations in southern Saudi Arabian UGIB patients, including both endoscopic and basic laboratory parameters, to assess the risk factors, and compare the predictive power and clinical usefulness of three risk scoring systems (AIMS65 score, Glasgow-Blatchford score, Rockall risk score) for the management of patients presenting with UGIB. 


\section{Subjects and methods Study design}

This was a retrospective record based observational study of consecutive patients admitted to the gastrointestinal unit at Abha City, southern Saudi Arabia, from November 2017 to October 2019.

\section{Study sample}

All patients with history of haematemesis, melena, hematochezia, or a combination of these symptoms were considered eligible for the study. Inclusion criteria were age more than 18 years, diagnosis of upper GI bleeding. Exclusion criteria were other reason for occult bleeding (e.g., anemia or iron deficiency), melena with no signs of bleeding revealed in endoscopy, pregnancy, and bleeding outside the upper gastrointestinal system.

\section{Data collection}

One author reviewed all medical records and entered the following information into a database: age and sex, smoking and GI symptoms, appearance of stool (red or maroon stool, melena, brown or yellow stool), comorbid diseases (acute or chronic kidney diseases, diabetes, hypertension, and cardiovascular diseases), and medications used within one month (NSAIDS, aspirin, and/or anticoagulants). Physical examinations included both systolic and diastolic blood pressure and heart rate at presentation.

The endoscopic findings were reported by a specialized endoscopist as follows: identification of the bleeding lesion, methods of endoscopic hemostasis (agent injection/sclerotherapy, embolization, clips, and band ligation procedures). Laboratory findings included complete blood count, albumin, urea, creatinine, prothrombin time, and activated partial thromboplastin time.

Upper gastrointestinal bleeding was defined as haematemesis or coffee grounds emesis, melena, or rectal bleeding with a confirmed cause of bleeding on upper endoscopy and a negative colonoscopy.

Re-bleeding was defined as recurrent haematemesis, hematochezia, or both; mortality was defined as any death occurring during the study period as result of the initial bleeding episode.
Scores of each patient were calculated based on their record's information. The AIMS65 score is an accurate risk score to predict in-hospital mortality, length of hospital stay, and health care costs in patients with acute UGIB. The AIMS65 consists of the following components: (A) albumin level $<3.0 \mathrm{~g} / \mathrm{dL}$, (I) international normalized ratio $>1.5$, (M) altered mental status, (S) systolic blood pressure $\leq 90 \mathrm{~mm}$ $\mathrm{Hg}$, and (65) age $>65$ years. When more than two components of the AIMS65 are present, the mortality risk is considered to be high [16]. The GBS is a formal risk assessment score for upper GI hemorrhages and uses the patient's blood results, blood pressure, known history and presentation findings to identify how urgently patients require endoscopic therapy [17]. The Rockall score, was developed to assess the risk of death following presentation with UGIB and incorporates patient age, hemodynamics, comorbidities and endoscopic findings. Rockall scores can be calculated both before and after endoscopy, but the post-endoscopic Rockall score provides a more accurate risk assessment [18].

\section{Statistical analysis}

Reports were collected, then coded and revised, and data were analyzed using the Statistical Package for Social Sciences logistic, version 20 (IBM Corp., Armonk, NY, USA). Ours was a descriptive study. The normality of continuous variables was tested using the Shapiro-Wilk test. All statistical analyses were done using two-tailed tests with an alpha error of 0.05. A P-value less than 0.05 was considered to be statistically significant. Frequencies and percentages were used to describe the categorical variables whereas means \pm standard deviations (SDs) were used to express continuous variables.

\section{Results}

The study included 283 patients with upper gastrointestinal tract bleeding disorders (Table 1). Patient ages ranged from 18 to 97 years old with mean age of $54.5 \pm 18.5$ years. The majority were males (72\%; 203). Melena was most common, reported in $66(49.3 \%)$ patients, followed by haematemesis (36.6\%), 13.4\% had melena with haematemesis, and $0.7 \%$ had coffee-ground emesis. The patients had mean systolic blood pressure of $112 \pm 17 \mathrm{~mm}$ Hg and diastolic blood pressure of $79 \pm 12 \mathrm{mmHg}$ with mean pulse rate $94 \pm 19 \mathrm{bpm}$. 
Table 1: Demographic data of patients with acute upper gastrointestinal tract bleeding in Abha, Saudi Arabia.

\begin{tabular}{|c|c|c|c|}
\hline \multicolumn{2}{|c|}{ Bio-demographic data } & No & $\%$ \\
\hline \multicolumn{4}{|l|}{ Age in years } \\
\hline & $<40$ & 66 & 23.30 \\
\hline & $40-60$ & 133 & 47.00 \\
\hline & $>60$ & 84 & 29.70 \\
\hline \multicolumn{4}{|l|}{ Gender } \\
\hline & Male & 203 & 72.00 \\
\hline & Female & 79 & 28.00 \\
\hline \multicolumn{4}{|c|}{ Presenting symptoms } \\
\hline & Hematemesis & 49 & 36.60 \\
\hline & $\begin{array}{l}\text { Coffee-ground } \\
\text { emesis }\end{array}$ & 1 & 0.70 \\
\hline & Melena & 66 & 49.30 \\
\hline & $\begin{array}{l}\text { Hematemesis + } \\
\text { Melena }\end{array}$ & 18 & 13.40 \\
\hline \multirow[t]{4}{*}{ Vital signs } & & Mean & $S D$ \\
\hline & SBP & 112 & 17 \\
\hline & DBP & 79 & 12 \\
\hline & Pulse rate & 94 & 19 \\
\hline
\end{tabular}

Figure 1 illustrates the reported risk factors among the study cases. Diabetes mellitus (DM) was the most frequently recorded risk factor for UGIB (53.9\%) followed by hypertension (44.9\%), aspirin (35.7\%), CLD (20.1\%), and steroid intake (15.2\%). The least recorded risk factors were celecoxib and alcohol intake (1.1\% for each category).

Endoscopic findings are summarized in Table 2. Esophageal endoscopy revealed esophageal varices in 65 patients (23\%), esophagitis in 30 (11.1\%), Mallory-Weiss tears in 4 (1.4\%), and esophageal ulcers in 14 (5\%). There were other signs of inflammation in 26 patients (9.3\%). Stomach endoscopy revealed that $6 \%$ of the patients had fundus ulcers, $4.9 \%$ had pyloric ulcers, and 2.8\% had antrum ulcers. Regarding ulcer description, 26 patients (9.2\%) had clean bases and ten (3.5\%) had adherent clots. On duodenal endoscopy, four patients (1.4\%) had mass at the duodenum, nine had vascular ectasia (3.2\%), and 63 (22.3\%) had an ulcer at the first part of the duodenum. Regarding descriptions of duodenal ulcers, it was clean based among 64 $(22.6 \%)$ cases and 6 cases $(2.1 \%)$ had black spot in the ulcer center while another six patients had nonbleeding visible vessels.

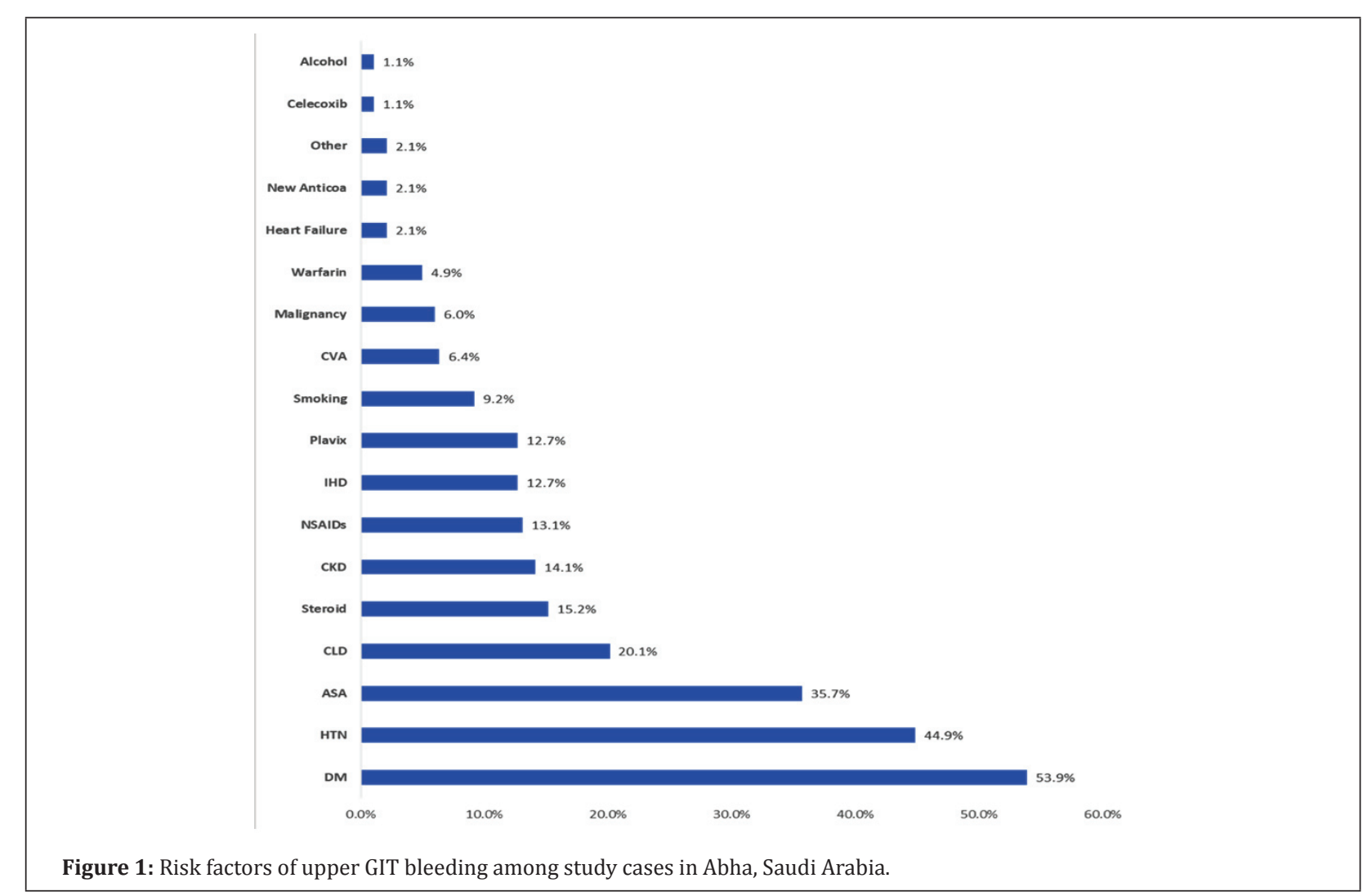


Table 2: Endoscopic findings among cases with upper gastrointestinal tract bleeding in Abha, Saudi Arabia.

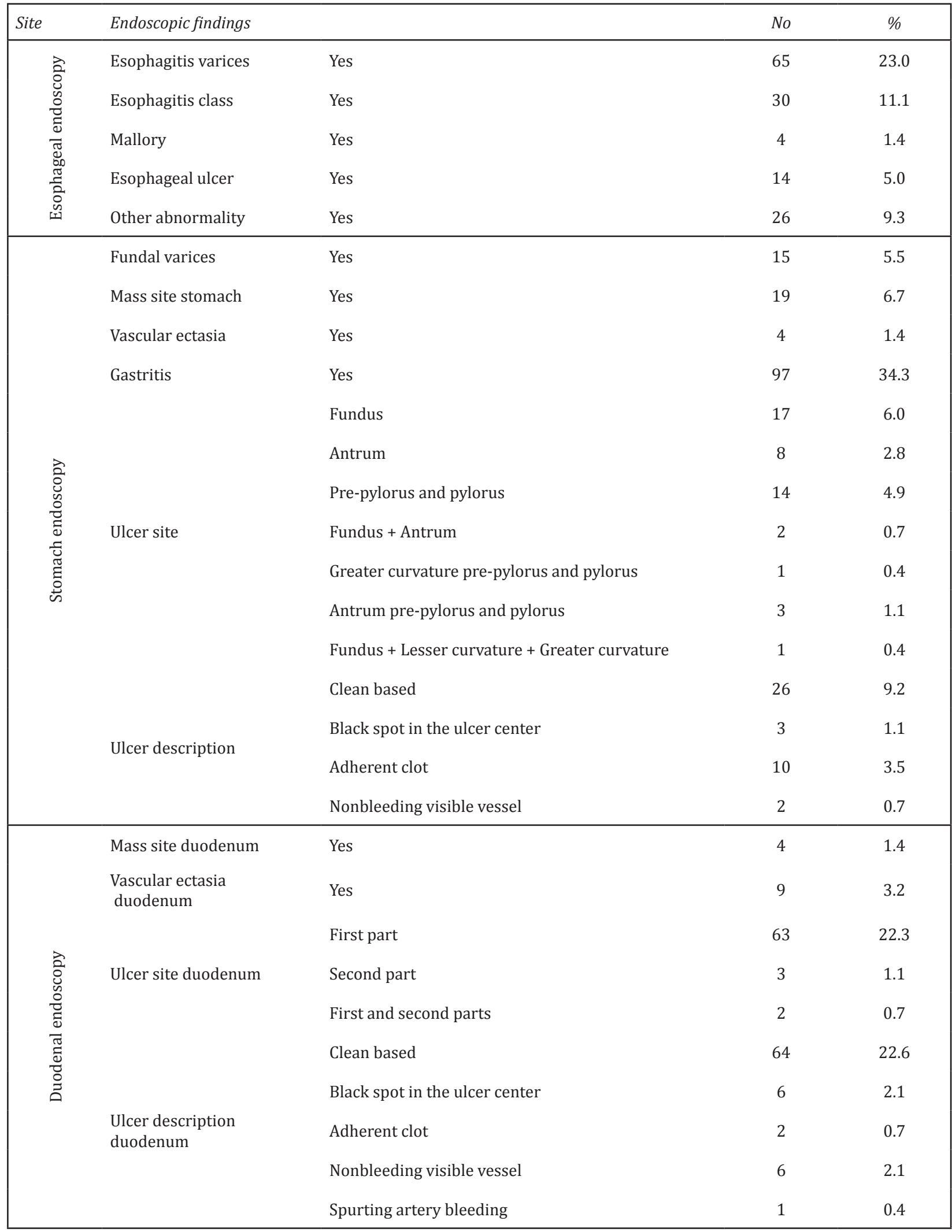

Table 3 demonstrates hemostasis measures among cases with upper GIT bleeding cases. Of these, 48 patients (17\%) underwent band ligation, 13 (4.6\%) underwent histoacryl glue, sclerotherapy injection, 
and four patients underwent band ligation with histoacryl glue. Bleeding was controlled among 189 cases (66.8\%) and 14 cases had re-bleeding (4.9\%). Only six patients required surgical intervention while seven underwent arterial embolization.

Laboratory findings of patients with acute upper GIT bleeding are displayed in Table 4. The mean hemoglobin level was $10.4 \pm 3.2 \mathrm{~g} / \mathrm{L}$, mean hematocrit of $32.1 \% \pm 8.8 \%$, mean WBCs of $8.9 \pm 5.8$, mean platelets of $224.4 \pm 132$, and mean albumin of $3.0 \pm$ 0.9 . Only one patient died $(0.4 \%)$.

Gastrointestinal bleeding score methods and their findings are displayed in Table 5. AIMS65 scores revealed that $61.5 \%$ had normal scores while transfusion requirement was reported in 88 patients (31.1\%). A total of 21 patients had serious score levels (7.4\%). GBS scores were normal for 18 patients $(6.4 \%)$ and serious outcome scores were recorded for 20 patients (7.1\%), while ICU admission or mortality were scored for 18 patients (6.4\%). RS scores revealed that none of the patients had normal scores while serious outcomes were detected in 26 patients (9.2\%). ICU admission scores were reported in 46 patients (16.3\%) (Table 6).

Table 3: Hemostasis measures among cases with upper gastrointestinal tract bleeding in Abha, Saudi Arabia.

\begin{tabular}{|llll|}
\hline Hemostatic measures & No & $\%$ \\
\hline & Band ligation & 48 & 17.0 \\
& $\begin{array}{l}\text { Histoacryl glue, } \\
\text { sclerotherapy injection }\end{array}$ & 13 & 4.6 \\
& Hemoclip & 2 & 0.7 \\
Endoscopic & Adrenaline injection & 2 & 0.7 \\
& Band ligation + & 4 & 1.4 \\
& $\begin{array}{l}\text { Histoacryl glue } \\
\text { Band ligation }+\end{array}$ & 1 & 0.4 \\
Hemoclip & 189 & 66.8 \\
Bleeding control & Yes & 14 & 4.9 \\
Re-bleeding & Yes & 6 & 2.1 \\
Surgery & Yes & 7 & 2.5 \\
$\begin{array}{l}\text { Arterial } \\
\text { embolization }\end{array}$ & Yes & & \\
\hline
\end{tabular}

Table 4: Laboratory findings of patients with acute upper gastrointestinal tract bleeding in Abha, Saudi Arabia.

\begin{tabular}{|lcc|}
\hline CBC & Mean & SD \\
\hline Hb & 10.4 & 3.2 \\
Hematocrit & 32.1 & 8.8 \\
PLT & 8.9 & 5.8 \\
INR & 224.4 & 132.0 \\
PT & 1.4 & 1.1 \\
APTT & 19.1 & 21.0 \\
Creatinine & 33.5 & 21.8 \\
Urea & 1.5 & 1.7 \\
Albumin & 62.0 & 53.8 \\
\hline
\end{tabular}

Table 5: Gastrointestinal tract bleeding score methods and their findings interpretation.

\begin{tabular}{|c|c|c|c|c|c|}
\hline Score & Findings & No & $\%$ & Range & $\begin{array}{l}\text { Mean } \\
(S D)\end{array}$ \\
\hline \multirow{3}{*}{$\begin{array}{l}\text { AIMS65 } \\
\text { score }\end{array}$} & Normal & 174 & 61.5 & \multirow{3}{*}{$0-2$} & \multirow{3}{*}{$\begin{array}{c}0.67 \\
(0.69)\end{array}$} \\
\hline & $\begin{array}{l}\text { Transfusion } \\
\text { requirement }\end{array}$ & 88 & 31.1 & & \\
\hline & Mortality & 21 & 7.4 & & \\
\hline \multirow{4}{*}{$\begin{array}{l}\text { Glasgow- } \\
\text { Blatchford } \\
\text { score }\end{array}$} & Normal & 18 & 6.4 & \multirow{4}{*}{$0-15$} & \multirow{4}{*}{$5.1(3.6)$} \\
\hline & $\begin{array}{l}\text { Transfusion } \\
\text { requirement }\end{array}$ & 227 & 80.2 & & \\
\hline & $\begin{array}{l}\text { Serious } \\
\text { outcome }\end{array}$ & 20 & 7.1 & & \\
\hline & $\begin{array}{l}\text { ICU } \\
\text { admission/ } \\
\text { mortality }\end{array}$ & 18 & 6.4 & & \\
\hline \multirow{4}{*}{$\begin{array}{l}\text { Rockall } \\
\text { risk score }\end{array}$} & Normal & 0 & 0.0 & \multirow{4}{*}{$1-11$} & \multirow{4}{*}{$4.8(2.9)$} \\
\hline & $\begin{array}{l}\text { Transfusion } \\
\text { requirement }\end{array}$ & 211 & 74.6 & & \\
\hline & $\begin{array}{l}\text { Serious } \\
\text { outcome }\end{array}$ & 26 & 9.2 & & \\
\hline & $\begin{array}{l}\text { ICU } \\
\text { admission/ } \\
\text { mortality }\end{array}$ & 46 & 16.3 & & \\
\hline
\end{tabular}


Table 6: Distribution of death cases by various gastrointestinal tract bleeding.

\begin{tabular}{|c|c|c|c|c|c|}
\hline Score & Findings & No & $\%$ & Range & $\begin{array}{c}\text { Mean } \\
(S D)\end{array}$ \\
\hline \multirow{3}{*}{$\begin{array}{l}\text { AIMS65 } \\
\text { score }\end{array}$} & Normal & 174 & 61.5 & \multirow{3}{*}{$0-2$} & \multirow{3}{*}{$\begin{array}{c}0.67 \\
(0.69)\end{array}$} \\
\hline & $\begin{array}{l}\text { Transfusion } \\
\text { requirement }\end{array}$ & 88 & 31.1 & & \\
\hline & $\begin{array}{l}\text { Serious/ } \\
\text { mortality }\end{array}$ & 21 & 7.4 & & \\
\hline \multirow{4}{*}{$\begin{array}{l}\text { Glasgow- } \\
\text { Blatchford } \\
\text { score }\end{array}$} & Normal & 18 & 6.4 & \multirow{4}{*}{$0-15$} & \multirow{4}{*}{$\begin{array}{c}5.1 \\
(3.6)\end{array}$} \\
\hline & $\begin{array}{l}\text { Transfusion } \\
\text { requirement }\end{array}$ & 227 & 80.2 & & \\
\hline & $\begin{array}{l}\text { Serious } \\
\text { outcome }\end{array}$ & 20 & 7.1 & & \\
\hline & $\begin{array}{l}\text { ICU } \\
\text { admission/ } \\
\text { mortality }\end{array}$ & 18 & 6.4 & & \\
\hline \multirow{4}{*}{$\begin{array}{l}\text { Rockall } \\
\text { risk score }\end{array}$} & Normal & 0 & 0.0 & \multirow{4}{*}{$1-11$} & \multirow{4}{*}{$\begin{array}{c}4.8 \\
(2.9)\end{array}$} \\
\hline & $\begin{array}{l}\text { Transfusion } \\
\text { requirement }\end{array}$ & 211 & 74.6 & & \\
\hline & $\begin{array}{l}\text { Serious } \\
\text { outcome }\end{array}$ & 26 & 9.2 & & \\
\hline & $\begin{array}{l}\text { ICU } \\
\text { admission/ } \\
\text { mortality }\end{array}$ & 46 & 16.3 & & \\
\hline
\end{tabular}

\section{Discussion}

About $72 \%$ of the study populations were males, where $47 \%$ of them aged between 40 and 60 years. The most common presenting symptom was melena (almost the half) as the commonest etiology was gastritis (34.3\%), duodenum ulcer (23.8\%), and esophagitis varices (23\%). In previous studies, haematemesis was the most frequent presenting complaint $[14,19]$. Duodenal ulcer was the commonest cause of UGIB in the past; however, recently, it was replaced by variceal bleeding due to cirrhosis because of the decreased prevalence of $H$. pylori and increased use of proton pump inhibitors $[5,14,20]$. A study from the northern region of Saudi Arabia reported that prevalence rate of gastric ulcer was two-fold higher than that of duodenal ulcer. The authors said that the use of NSAIDs, $H$. pylori infection, and stress were among the main reason behind this [21].

Endoscopic hemostatic treatment was applied in 70 patients (24.7\%); $4.9 \%$ of patients re-bled, and only one patient (1.4\%) died during the study period. Our results showed that males were predominant, with a ratio of 2.6:1. This accord with an old Saudi Arabian study and previous reports from various countries where UGIB was more common in males than in females [5, 12, 20]. Furthermore, we demonstrated that older age, current comorbid diseases, especially DM and hypertension, and use of certain drugs were associated with the risk of developing UGIB. Previous studies also supported our findings on clinical conditions in patients with UGIB [22].

The use of low-dose ASA in patients with chronic cardiovascular diseases was associated with increased risk of gastrointestinal bleeding, consistent with findings of a recent Turkish review [6].

Only $4.9 \%$ of patients with UGIB re-bled, significantly lower than other rates reported in previous studies inside and outside Saudi Arabia (11\%-18\%). The mortality rate was also small compared to the death rate indicated in previous reports, where these rates varied from $1.8 \%$ to $20.3 \%$. This discrepancy might be due to the higher number of participants in these studies compared to our limited sample size [14, $15,23-25]$. Cheng et al. reported a similar mortality rate $(0.5 \%)$ [26]. We have reported that endoscopic treatment was used for patients with upper GIS hemorrhage at a rate of $24.7 \%$. A similar rate was reported in a previous study [26]; however, this rate was lower than that reported by Uysal et al. (38.1\%). Past research indicated endoscopic treatment of patients with upper gastrointestinal bleeding varied between $24 \%$ and $40.3 \%$ [26-29].

In our study, we compared the performance of GBS, RS, and AIMS65 scoring systems in predicting primary and secondary outcomes in patients with UGIB. The AIMS65 score was more effective and accurate than the two others in predicting mortality, which is reasonable given that this was the primary purpose of the AIMS65 score [30]. The GBS was developed to predict and assess low-risk UGIB, whereas the RS was created to avoid re-bleeding and death of individuals with upper GI hemorrhage [8]. Some studies returned the same findings or did not reported a superior scoring system [31-33]. By contrast, western studies reported the superiority of Glasgow Blatchford score to the other scores, even in terms of predicting death $[24,26]$. For these reasons, argument persists regarding the ideal scoring system that is consistently relevant in clinical sites and predicts all kinds of clinical events. 
This present study has some limitations. The retrospective design limits the temporality of the findings. In addition, our study included a single center with a relatively small sample size, possibly causing restriction in the generalizability and power of its findings. Nevertheless, our data (including endoscopic, laboratory and clinical information) were of high quality because all medical records were present and reviewed. Despite its limitations, this is the first study in southern Saudi Arabia to discuss clinical manifestations of UGIB patients and to compare different scoring systems.

\section{Conclusion}

There has been a substantial change in the trend of UGIB in southern Saudi Arabia over the past decades, as in other parts of the world; nevertheless, UGIB remains a life-threatening condition, especially among elderly people. Comorbidities such as hypertension and diabetes, in addition to some medicines including ASA, steroids and NSAIDs were identified as risk factors of upper GIT bleeding among this study cases, leading to hospitalization and even death.. Our findings may support specialists and those in general practice, where emergency EGD is generally unavailable, to determine optimal treatment approaches more accurately.

\section{Conflicts of interest}

Authors declare no conflicts of interest.

\section{References}

[1] Han YJ, Cha JM, Park JH, Jeon JW, Shin HP, et al. Successful endoscopic hemostasis is a protective factor for rebleeding and mortality in patients with nonvariceal upper gastrointestinal bleeding. Dig Dis Sci. 2016; 61(7):20112018.

[2] Lam KLY, Wong JCT, Lau JYW. Pharmacological treatment in upper gastrointestinal bleeding. Curr Treat Options Gastroenterol. 2015; 13(4):369-376.

[3] Pongprasobchai S, Nimitvilai S, Chasawat J, Manatsathit S. Upper gastrointestinal bleeding etiology score for predicting variceal and non-variceal bleeding. World J Gastroenterol. 2009; 15(9):1099-1104.

[4] Alharbi A, Almadi M, Barkun A, Martel M, REASON Investigators. Predictors of a variceal source among patients presenting with upper gastrointestinal bleeding. Can J Gastroenterol. 2012; 26(4):187-192.

[5] Danýp N, Tekin F, Akarca US, Ünal NG, Ipýk Erdoðan E, et al. Changing patterns of upper gastrointestinal bleeding over 23 years in Turkey. Turk J Gastroenterol. 2019; 30(10):877882.

[6] Dinçer D, Ulukal Karancý E, Akýn M, Adanýr H. NSAID, antiaggregant, and/or anticoagulant-related upper gastrointestinal bleeding: Is there any change in prophylaxis rate after a 10-year period? Turk J Gastroenterol. 2019; $30(6): 505-510$.
[7] Abougergi MS. Epidemiology of upper gastrointestinal hemorrhage in the USA: Is the bleeding slowing down? Dig Dis Sci. 2018; 63(5):1091-1093.

[8] Choe JW, Kim SY, Hyun JJ, Jung SW, Jung YK, et al. Is the AIMS 65 Score useful in prepdicting clinical outcomes in Korean patients with variceal and nonvariceal upper gastrointestinal bleeding? Gut Liver. 2017; 11(6):813-820.

[9] Barkun AN, Bardou M, Kuipers EJ, Sung J, Hunt RH, et al. International consensus recommendations on the management of patients with nonvariceal upper gastrointestinal bleeding. Ann Intern Med. 2010; 152(2):101-113.

[10] Loperfido S, Baldo V, Piovesana E, Bellina L, Rossi K, et al. Changing trends in acute upper-GI bleeding: a populationbased study. Gastrointest Endosc. 2009; 70(2):212-224.

[11] Abougergi MS, Travis AC, Saltzman JR. The in-hospital mortality rate for upper GI hemorrhage has decreased over 2 decades in the United States: a nationwide analysis. Gastrointest Endosc. 2015; 81(4):882-888.e1.

[12] Al Karawi MA, Ghandour Z, Mohamed A el S. Causes of upper gastrointestinal bleeding: Experience at a major hospital in Riyadh. Ann Saudi Med. 1995; 15(6):606-608.

[13] Ahmed ME, al-Knaway B, al-Wabel AH, Malik GM, Foli AK. Acute upper gastrointestinal bleeding in southern Saudi Arabia. J R Coll Physicians Lond. 1997; 31(1):62-64.

[14] Masoodi I, AlQurashi H, Al Sofiyani Md. Changing trends in acute upper GI bleeding a single-centre study in the western region of Saudi Arabia. BJMP. 2019; 12(3):a019

[15] Uysal Y, Babus SB, Kose A, Ates F, Biricik S, et al. The prognostic significance of the risk scores at upper gastrointestinal bleeding. Niger J Clin Pract. 2019; 22(8):1099-1108.

[16] Thandassery RB, Sharma M,John AK, et al. Clinical application of AIMS65 scores to predict outcomes in patients with upper gastrointestinal hemorrhage. Clin Endosc. 2015; 48(5):380384.

[17] Chatten K, Purssell H, Banerjee AK, Soteriadou S, Ang Y. Glasgow Blatchford score and risk stratifications in acute upper gastrointestinal bleed: can we extend this to 2 for urgent outpatient management?. Clin Med (Lond). 2018; 18(2):118-122.

[18] Wang CY, Qin J, Wang J, Sun CY, Cao T, et al. Rockall score in predicting outcomes of elderly patients with acute upper gastrointestinal bleeding. World J Gastroenterol. 2013; 19(22):3466-3472.

[19] Minakari M, Badihian S, Jalalpour P, Sebghatollahi V. Etiology and outcome in patients with upper gastrointestinal bleeding: Study on 4747 patients in the central region of Iran. J Gastroenterol Hepatol. 2017; 32(4):789-796.

[20] Hreinsson JP, Kalaitzakis E, Gudmundsson S, Björnsson ES. Upper gastrointestinal bleeding: incidence, etiology and outcomes in a population-based setting. Scand J Gastroenterol. 2013; 48(4):439-447.

[21] Albaqawi ASB, El-Fetoh NMA, Alanazi RFA, Alanazi NSF, Alrayya SE, et al. Profile of peptic ulcer disease and its risk factors in Arar, Northern Saudi Arabia. Electron Physician. 2017; 9(11):5740-5745.

[22] Gallerani M, Simonato M, Manfredini R, Volpato S, Vigna GB, et al. Risk of hospitalization for upper gastrointestinal tract bleeding. J Clin Epidemiol. 2004; 57(1):103-110.

[23] Dicu D, Pop F, Ionescu D, Dicu T. Comparison of risk scoring systems in predicting clinical outcome at upper gastrointestinal bleeding patients in an emergency unit. Am J Emerg Med. 2013; 31(1):94-99. 
[24] Stanley AJ, Dalton HR, Blatchford O, Ashley D, Mowat C, et al. Multicentre comparison of the Glasgow Blatchford and Rockall Scores in the prediction of clinical end-points after upper gastrointestinal haemorrhage. Aliment Pharmacol Ther. 2011; 34(4):470-475.

[25] Onder A, Kapan M, Taskesen F, Aliosmanoglu I, Arikanoglu Z, et al. Risk factors in non-variceal and non-malignancy upper gastrointestinal system bleedings in the patients undergoing surgery. Turk J Surg. 2011; 27(4):216.

[26] Cheng DW, Lu YW, Teller T, Sekhon HK, Wu BU. A modified Glasgow Blatchford Score improves risk stratification in upper gastrointestinal bleed: a prospective comparison of scoring systems. Aliment Pharmacol Ther. 2012; 36(8):782789 .

[27] Farooq FT, Lee MH, Das A, Dixit R, Wong RCK. Clinical triage decision vs risk scores in predicting the need for endotherapy in upper gastrointestinal bleeding. Am J Emerg Med. 2012; 30(1):129-134.

[28] Bryant RV, Kuo P, Williamson K, Yam C, Schoeman MN, et al. Performance of the Glasgow-Blatchford score in predicting clinical outcomes and intervention in hospitalized patients with upper GI bleeding. Gastrointest Endosc. 2013; 78(4):576-583.

[29] Pang SH, Ching JYL, Lau JYW, Sung JJY, Graham DY, et al. Comparing the Blatchford and pre-endoscopic Rockall score in predicting the need for endoscopic therapy in patients with upper GI hemorrhage. Gastrointest Endosc. 2010; 71(7):1134-1140.

[30] Saltzman JR, Tabak YP, Hyett BH, Sun X, Travis AC, et al. A simple risk score accurately predicts in-hospital mortality, length of stay, and cost in acute upper GI bleeding. Gastrointest Endosc. 2011; 74(6):1215-1224.

[31] Nakamura S, Matsumoto T, Sugimori H, Esaki M, Kitazono T, et al. Emergency endoscopy for acute gastrointestinal bleeding: prognostic value of endoscopic hemostasis and the AIMS65 score in Japanese patients. Dig Endosc Off J Jpn Gastroenterol Endosc Soc. 2014; 26(3):369-376.

[32] Robertson M, Majumdar A, Boya pati R, Chung W, Worland $\mathrm{T}$, et al. Risk stratification in acute upper GI bleeding: comparison of the AIMS65 score with the GlasgowBlatchford and Rockall scoring systems. Gastrointest Endosc. 2016; 83(6):1151-1160

[33] Hyett BH, Abougergi MS, Charpentier JP, Kumar NL, Brozovic $\mathrm{S}$, et al. The AIMS65 score compared with the GlasgowBlatchford score in predicting outcomes in upper GI bleeding. Gastrointest Endosc. 2013; 77(4):551-557. 